\title{
TOLSTOI Y GANDHI: LA RESISTENCIA PASIVA Y EL REINO DE DIOS
}

\section{TOLSTOI AND GANDHI: PASSIVE RESISTANCE AND THE KINGDOM OF GOD}

\author{
Pedro CARRERo ERAS
}

UNIVERSIDAD DE ALCALÁ

\begin{abstract}
Resumen: El objetivo del presente estudio se centra en un aspecto no lo suficientemente estudiado en nuestro país: la influencia de León Tolstoi y de su obra El reino de Dios está en vosotros en M. K. Gandhi, especialmente en todo lo que tiene que ver con la abolición de la guerra y con los recursos de la resistencia pasiva y la no violencia como medios para conseguir un mundo más justo y pacífico. En el trabajo se analiza cómo la lectura de esa obra por Gandhi vino a superponerse a su conocimiento de obras como el Bahagavad-Gìtā y el Nuevo Testamento, especialmente el Sermón de la Montaña, obras, junto a otras de autores contemporáneos, de las que el futuro Mahatma extrajo gran parte de sus fundamentos ideológicos que tienen como base la ahim sā o no-violencia y el sincretismo, que le conducirían a la satyägraha o «insistencia en la verdad», ideología que empezó a desarrollar durante sus ańos de estancia en Sudáfrica, y que trasciende lo meramente político, pues afecta a muchos otros aspectos de la condición humana. En el tema de las influencias recibidas se destacan, además, las ideas de John Ruskin en su libro Unto This Last y las de Henry David Thoreau en Desobediencia civil. El estudio profundiza también, aportando nuevos datos bibliográficos, en la relación epistolar entre Tolstoi y Gandhi, sin olvidar la influencia que el autor ruso tuvo en la creación de los ashrams fundados por Gandhi.
\end{abstract}

Palabras clave: Gandhi; Discriminación de los indios en Sudáfrica; No violencia; Resistencia pasiva; Desobediencia civil; Ahimsää Satyāgraha; Sincretismo; Tolstoi: El reino de Dios está en vosotros; Abolición de la guerra y del servicio militar; John Ruskin: Unto this last; H. D. Thoreau: Desobediencia civil; Creación de ashrams. 
АвsтRACT: This paper aims to focus on an aspect which had not been sufficiently studied in our country so far: the influence of Leo Tolstoy and his work The Kingdom of God Is within You on M. K. Gandhi, especially as regards everything related to the abolition of war and the resources of passive resistance and non-violence as a means to achieve a more just and peaceful world. The paper analyses how Gandhi's reading of this work came to overlap his knowledge of certain works (Bahagavad-Gìt $\bar{a}$ and the New Testament, particularly the Sermon on the Mount, along with others by contemporary authors). The future Mahatma extracted a great part of the ideological foundations based on ahimsā or non-violence and syncretism from this works, and this would lead him to satyaggraha or 'insistence on the truth' - an ideology he started to develop in his South African years, transcending merely political issues to impact many other aspects of the human condition. Further noteworthy influences that can be highlighted are the ideas that John Ruskin outlined in his book Unto This Last and those of Henry David Thoreau in Civil Disobedience. Contributing with new bibliographical information, the study also goes into the epistolary relationship between Tolstoy and Gandhi in depth, without forgetting the inspiration that the Russian author exerted on the creation of the ashrams founded by Gandhi.

Key Words: Gandhi; Discrimination of the Indians in South Africa; Non-violence; Passive resistance; Active non-violence; Civil disobedience; Ahimsā̄; Satyägraha; Syncretism; Tolstoy: The Kingdom of God Is within You; Abolition of war and military service; John Ruskin: Unto This Last; H. D. Thoreau: Civil Disobedience; Creation of ashrams.

Deseo aclarar, antes de entrar en materia, que he elegido la expresión «resistencia pasiva» como punto de partida de este estudio, y bien a sabiendas de que el propio Gandhi, no satisfecho del todo tal y como se solía interpretar esta expresión, que usó en sus primeros tiempos, prefirió sustituirla por la de satyāgraha, que explico más pormenorizadamente en el apartado $7^{\circ}$. De cualquier forma, un complejo entramado léxico hace que, en el uso común, funcionen en la historia contemporánea con significado, si no idéntico, sí muy relacionado, expresiones como non-violence, passive resistance, active non-violence, civil disobedience, etc.

\section{La cruda realidad para un indio en Sudáfrica}

En África del Sur, hacia finales de mayo de 1893, un joven abogado indio, vestido como un auténtico gentleman inglés, viajaba en la primera clase de un tren en dirección a Pretoria. Este abogado, que había estudiado y se había licenciado en Londres, y que se llamaba Mohandas Karamchand Gandhi, hacía poco 
que acababa de llegar a Sudáfrica para trabajar con la firma Daba Abdula \& Company y, en concreto, para intervenir en un proceso en el que estaba en juego una gran cantidad de dinero. Ese tren en el que viajaba se detuvo en Maritzburg, la capital de Natal, y en esa estación subió un hombre blanco que también viajaba en primera clase. Al descubrir el blanco que en ese mismo vagón había un hombre de piel oscura, se quejó ante los empleados de ferrocarril, que solicitaron a Gandhi que se trasladara al vagón de tercera. Al negarse, aduciendo que había comprado un billete de primera clase, llegó un policía, y con cajas destempladas agarró a Gandhi de una mano y le arrojó fuera del vagón, así como su equipaje.

Este detestable suceso de racismo no iba a ser el único que sufriera el joven y atildado abogado indio, que por aquellos entonces todavía creía en la justicia británica y se sentía como un ciudadano más del Imperio. Como señala Heimo Rau, uno de los biógrafos del Mahatma, con el incidente de Maritzburg, "comenzó un largo calvario de humillaciones para Gandhi ${ }^{1}$ », pues tuvo que soportar otra brutalidad parecida en el siguiente viaje, que fue en coche de caballos entre Charlestown y Johannesburgo, trayecto en el que no existía el ferrocarril. Aunque tenía billete de primera, «el hombre blanco responsable» de la diligencia le obligó a viajar en el pescante, al lado del conductor. En su autobiografía, Gandhi nos cuenta la indignación que sintió por dentro:

Yo sabía que esto era una incalificable injusticia y un insulto, pero tuve que aceptar una y otro. No hubiera podido lograr que me dejasen sentar dentro del coche, y en el caso de haber protestado la diligencia habría partido simplemente sin mí, lo que hubiera traído aparejada la pérdida de otro día más ${ }^{2}$.

Pero ahí no acabaría todo, pues ese mismo hombre blanco que le había obligado a sentarse en el pescante, decidió, caprichosamente, salir a tomar el

1 Heimo Rau, Gandhi, Barcelona, Salvat, 1987, p. 51.

2 Mahatma Gandhi, Autobiografia. Historia de mis experiencias con la verdad, Madrid, Gaia, primera reimpresión, 2016, p. 101. Llamo la atención sobre el hecho de que el subtítulo original, en inglés, es The Story of my Experiments with Truth, por consiguiente, el término adecuado en castellano es experimentos y no experiencias que, quizá para darle al título de la obra una dimensión distinta, figura en la traducción que cito. 
aire fresco y fumar, justo donde Gandhi estaba sentado, al que ahora obligó a colocarse en el estribo. En ese punto, Mohandas se negó, aunque dijo que estaba dispuesto a sentarse dentro del coche, por lo que ese hombre comenzó a golpearle y casi estuvo a punto de bajarle a rastras, pero Gandhi resistió y, según cuenta él mismo: «...yo me aferré a los hierros del pescante, decidido a mantenerme allí aunque me quebrara los huesos de las muñecas» ${ }^{3}$. La gente que iba dentro del coche se conmovió ante la resistencia del joven de piel oscura, por lo que recriminó a aquel blanco energúmeno e invitó a Gandhi a sentarse dentro.

He querido comenzar este estudio con la referencia a esos hechos de racismo y segregación que no son en modo alguno ni anecdóticos ni irrelevantes en la vida del futuro Mahatma, pues, aparte de evocarlos él con todo detalle en sus memorias, explican en buena medida cómo Gandhi habría de movilizarse rápidamente para defender los derechos de los indios en Sudáfrica. Los que le habían contratado y otros amigos indios sonrieron cuando Gandhi les contó lo que le había ocurrido en el ferrocarril y en la diligencia, y confesaron que ellos mismos soportaban a menudo situaciones parecidas.

Hasta su llegada a Sudáfrica, Gandhi había tenido algún incidente con los británicos, pero no se había tenido que enfrentar tan crudamente con las desigualdades provocadas por el color de la piel. Es verdad que cuando ejercía como abogado en Rajkot, y representando a su hermano en un turbio litigio, había sido echado con malos modos de la casa de un agente político británico, sir Edward Charles Ollivant. Como señala Stanley Wolpert en su biografía de Gandhi:

[...] la expulsión violenta del despacho de Ollivant alteró instantáneamente la imagen entusiasta que [Gandhi] había pintado en su mente del honor, la justicia, los buenos modales y el comportamiento amistoso de los ingleses ${ }^{4}$.

\section{Ibid.}

4 Stanley Wolpert, Gandhi, [título original, Gandhi’s Passion], Barcelona, Folio, 2003, p. 61. Ollivant representaba al virrey en los principados de Rajkot y Porbandar. Se había acusado al hermano de Gandhi, Lakshmidas, haber aconsejado a un joven llamado Rana sustraer piedras preciosas del principado sin consultar antes al agente británico. Lakshmidas animó a su hermano a que fuera a hablar con Ollivant, pues Mohandas le había conocido en Londres. Sin embargo, cuando Gandhi se entrevistó con Ollivant, este apenas le escuchó y mandó a su criado que lo expulsara de la casa, como así hizo. Dice Gandhi en su autobiografía: «...llegó 
Es decir, que aquel incidente fue una primera desilusión, aunque momentánea, respecto a los británicos, pero ni en la India ni en su estancia en el Londres victoriano había tenido que sufrir las humillaciones que le aguardaban, como un brutal recibimiento, en Sudáfrica.

El padre de Gandhi, Karamchand Gandhi, había sido primer ministro en el principado de Porbandar en Gujarat, y después en Rajkot. La familia de Gandhi pertenecía a la casta moh-vāniyā, subcasta de los vaiśya ${ }^{5}$, mercaderes (famosos por su habilidad en los negocios y su honradez), pero en los últimos tiempos sus miembros se habían dedicado más a actuar en la pequeña política de los principados. Cuando Karamchand se trasladó a Rajkot para servir a un príncipe indio más poderoso, el pequeño Mohandas, de siete años, fue matriculado en la Alfred High School, donde comenzó a aprender inglés.

El joven Mohandas, gracias al apoyo material y moral de su hermano mayor, pudo cursar estudios superiores en Londres. Y digo moral porque gracias a sus gestiones pudo convencer, a medias, a la casta. No pudo evitar que una parte le excomulgara, porque se consideraba que un viaje así de un joven, a una ciudad de Occidente, tendría necesariamente que corromperle. El hermano consiguió que Mohandas viajara, y después de que Mohandas prometiera solemnemente a la madre que no comería carne.

Su estancia en la metrópoli (1888-1891) le permitiría a Gandhi no solo licenciarse en Derecho, sino también empaparse de la cultura de Gran Bretaña, leer un buen número de libros, frecuentar a muchas personas, es decir, a muchos británicos, ser miembro de una sociedad vegetariana y publicar varios artículos. Durante esa época, y mucho antes de que el abogado Gandhi se transformara en el Mahatma, vestía como los británicos, a los que admiraba por sus leyes, su poder y su cultura. Pero todo eso se vino abajo cuando llegó a Sudáfrica. Gandhi fue considerado y tratado como un culi (coolie $)^{6}$, término despectivo con el que

el asistente, plantó ambas manos sobre mis hombros y me empujó fuera de la habitación» (op. cit., p. 61).

5 Para la denominación y transliteración de las castas sigo la terminología que figura en el glosario de la extensa y documentada obra de Agustín Pániker sobre la sociedad de castas: «moh-vāniyā, casta de comerciantes de Guyarat» (Agustín Pániker, La sociedad de castas. Religión y política en la India, Barcelona, Kairós, 2014, glosario, p. 653). En castellano, esta casta suele escribirse como bania, aunque a veces también aparece con la forma vania.

6 Ibid., p. 645: «coolie: porteador, peón. La palabra parece proceder de la tribu gujarati culi, aunque quizá de la urdu qulì, que significa "esclavo"». 
los británicos llamaban a los trabajadores indios que habían emigrado a Natal con un contrato de cinco años. Ese término también llegaron a usarlo para designar a los comerciantes musulmanes indios y a los parsis. No es difícil imaginar la irritación del joven Mohandas al sentirse maltratado por gente que no tenía los modales, la educación y los estudios que él había alcanzado.

Gandhi se interesaría enseguida por una serie de decretos que eran claramente discriminatorios para los indios, y se pondría en acción, de manera que su labor en África del Sur como abogado quedó supeditada a toda una serie de reclamaciones y protestas que encabezó, al darse cuenta de que las personas como él no eran, de verdad, tratadas como otros súbditos británicos del Imperio, sino de manera bien distinta. En el Estado Libre de Orange -que después sería una provincia de Sudáfrica-, una ley especial había derogado todos los derechos de los indios, y solo tenían la posibilidad de trabajar en oficios considerados serviles, como, por ejemplo, camareros. Se expulsó a los comerciantes y se les incautaron sus propiedades, sin derecho a cobrar indemnización. En el Traansval un decreto imponía a todo indio que entraba en el país un depósito de tres libras. No tenían derecho al voto, ni la posibilidad, en la mayor parte del territorio, de poseer tierras. Tampoco podían acceder a los parques públicos ni salir de casa después de las nueve de la noche. El cumplimiento de estas leyes discriminatorias dependía de las autoridades y, en cada caso, del buen o mal humor de los representantes de la ley a la hora de aplicarlas?

\section{La ahimssā o no-violencia: la Gītā y el Sermón de la Montaña. La paradoja de la $G \bar{t} t \bar{a}$}

La esencia de la actuación política de Gandhi ante los abusos y las desigualdades se forja ya en sus años de estancia en Sudáfrica. Pero esa actuación tiene una profunda base filosófica y religiosa. El joven Mohandas ya desde sus años de estancia en Londres había comenzado a leer una serie de obras no solo del hinduismo, sino también de otras religiones, como el cristianismo. Allí en Londres, su amigo y compañero de habitación Josiah Olfied, como «buen cristiano» que era, intentó convertir a Gandhi al anglicanismo, recomendándole que leyera la Biblia, lo que así hizo. Todo parece indicar que el Nuevo Testamento le debió

Cf. Heimo Rau, op. cit., pp. 51-52. 
parecer a Mohandas mucho más atractivo que el Antiguo, pues sabemos que le atrajo, muy poderosamente, el Sermón de la Montańa:

El Nuevo Testamento me causó una impresión muy distinta, especialmente el Sermón del Monte, que llegó derechamente a mi corazón. Lo comparé con el Gita. Los versículos: «Mas yo os digo: no resistáis al mal; antes, a cualquiera que te hiriere en tu mejilla diestra, devuélvele también la otra; y al que quisiere ponerte a pleito y tomarte tu ropa, déjale también la capa» me encantaron más allá de toda ponderación» ${ }^{8}$.

Antes de leer la Biblia, Gandhi había leído la Bhagavad-Gītā, canción formada, como es sabido, por 700 versos del Mahäbārata, el poema épico -y, por tanto, de guerra- más extenso del que se tiene noticia. Fue hacia el segundo año de su permanencia en Londres, es decir en 1889, al entrar en relación con dos teósofos, cuando se produjo esa lectura. Antes tuvo que confesar a sus amigos, avergonzado, que no había leído la Gìtāa, ni en sánscrito ni en gujarati. Leyó el poema con ellos, basándose en la traducción de sir Edwin Arnold, y Gandhi aportó lo que podía, de sus conocimientos de sánscrito, para ver si la traducción se correspondía al original. Esa lectura se convirtió en verdadero estudio en años posteriores, y en toda una guía espiritual para Gandhi, según confiesa él mismo en sus memorias: «Hoy considero la Gita como el libro por excelencia para el conocimiento de la verdad» ${ }^{9}$. Y no olvidemos que la búsqueda de la verdad, en su pensamiento político, es esencial. Por esas fechas de su estancia en Londres, Mohandas conoció, a través de sus amigos teósofos, a Madame Blavatsky y a su discípula Annie Besant, que habría de sucederla. Los teósofos le invitaron a Gandhi a entrar en la Sociedad Teosófica, pero él rechazó la invitación con cortesía, declarando que «con mis escasos conocimientos de mi propia religión no quiero pertenecer a ninguna institución religiosa» ${ }^{10}$. Creo que, aunque Gandhi habría de tender al sincretismo en su pensamiento religioso, pues veía en todas las religiones, y no solo en una en exclusiva, la manifestación de la divinidad, este motivo, tan querido y practicado por los teósofos -y tan admirable-, unido a su búsqueda de la fraternidad universal, no fue suficiente para que se adscribiera a

8 Cf. Gandhi, Autobiografía, op. cit., p. 67. Ver el pasaje citado en los Evangelios de San Mateo, 5, 39-42 y San Lucas, 6, 29-30.

9 Ibid., p. 66.

10 Ibid. 
la Sociedad Teosófica. Gandhi estaba en esa época viviendo una búsqueda de la verdad que le llevaba a un conocimiento apasionado de las grandes religiones, pero fue siempre crítico con aquellos aspectos que no le convencían, ya fueran del cristianismo o del propio hinduismo.

En esa persecución de la verdad que le llevaba a establecer relaciones entre unas religiones y otras, para Gandhi el código moral de la Gĩtā se corresponde con la esencia del Sermón de la Montaña. Dice el Mahatma en una de sus reflexiones:

No he podido ver ninguna diferencia entre el Sermón de la Montaña y la Bhagavad Gita. Lo que el sermón describe de una manera gráfica, la Bhagavad Gita lo reduce a una fórmula científica. Puede que no sea un libro científico en el sentido corriente de la palabra, pero ha hablado de la ley del amor [...] de una manera científica. El Sermón de la Montaña ofrece la misma ley en un lenguaje maravilloso. [...] Hoy, si me viera privado de la Gita y olvidara todo su contenido, pero tuviera un ejemplar del Sermón, este me proporcionaría la misma alegría que me proporciona la Gita ${ }^{11}$.

Pero si la Gìtā, en una primera lectura, se puede considerar como una justificación de la guerra ¿cómo puede Gandhi haber extraído de este poema la idea de la no-violencia? Es como una paradoja, pero que, sin embargo, tiene su explicación (sin olvidar que este texto ha sido objeto de innumerables y a veces contradictorias interpretaciones). Recordemos la situación bélica de su argumento: los Pandava, que representan el bien, y a cuyo frente está Arjuna, reclaman a los Kaurava, que representan el mal, el cumplimiento de un pacto según el cual ha llegado el momento para que se les entregue el reino de los Baratha, pero los Kaurava se niegan, de manera que se entabla una batalla, la de

\footnotetext{
11 El pensamiento de Gandhi. Antología. Selección e introducción de David Williams, Barcelona, Olañeta, Los pequeños libros de la sabiduría, 2013, p. 23. Como es sabido, la BhagavadGītā se conoce abreviadamente como Gītā. En sánscrito, puesto que se refiere a 'la canción', es femenino, aunque en español a veces se suele emplear como masculino, por hacer referencia no a la canción sino a 'el canto'. Véase, por ejemplo, el artículo que cito en la nota núm. 13. En este estudio empleo la forma femenina, pero respeto la masculina en las citas cuando aparece como tal.
} 
Kurukshetra. Krishna, que apoya a los Pandava, se le aparece a Arjuna antes de la batalla. Arjuna ha visto en el campo enemigo a guerreros que conoce bien, así como a familiares y amigos por los que siente admiración y veneración. Entonces, abrumado por todo ello, Arjuna arroja su arco y se niega a luchar, e incluso decide convertirse en renunciante. Pero Krishna le reprocha su debilidad, y le recuerda que el deber de todo guerrero (su dharma) es enfrentarse al enemigo sin pensar en los resultados, es decir, sin dejarse tentar por el deseo de los frutos de las propias acciones. Se debe cumplir con el deber y no hay que preocuparse de los resultados. Al llegar a este punto, que constituye el primer capítulo, lo que sigue en la Bhagavad-Gìtā está constituido por las enseñanzas de Krishna a Arjuna, y que el dios define como un yoga.

De todas formas, y como bien señala el filósofo Fernando Díez: «...a muchos les resulta curioso que un texto como la Bhagavad-Gìtāa, que lleva los valores éticos a su extremo, comience justificando una batalla entre hermanos ${ }^{\prime 2}$. De hecho, la mayoría de los exegetas que han interpretado esta canción ven en ella una justificación religiosa de la guerra. Para ello, debemos tener en cuenta que Krishna le recuerda a Arjuna que debe cumplir con su dharma, el que corresponde a su casta, que es la de los kșatriya, los guerreros, para los cuales luchar es su deber, así como mantener el bien y el orden, por lo que si alguien mata o muere, eso es una consecuencia de su karma. Además, la violencia que se desarrolla en el campo de batalla solo afecta a los cuerpos mortales de los que luchan, mientras que el àtman, es decir, el alma individual, es eterno, imperecedero, existe en todo lo que es y, por supuesto, tanto en los guerreros de un bando como en los del otro.

El investigador Salvador Cuenca Almenar estudia en un extenso artículo cómo Gandhi extrae de la Gītā, de un texto que comienza con una batalla, su concepto de la ahimsāa, es decir, de la no-violencia, aunque resulte paradójico. Según este autor, Gandhi, en su lectura de la obra

[...] desvió el foco de atención de las estrofas 31-38 a las 53-72 del capítulo II de la Gita. [...] Las estrofas 31-38 inspiran los comentarios belicistas

12 Fernando Díez, El legado de la India, Madrid, Mandala, 2005, p. 136. 
de la Gita, mientras que las 53-72 inspiran la justificación de la práctica de la ahimsa ${ }^{13}$.

Basándose en esos versos o śloka del capítulo II de la Gītā que atrajeron a Gandhi, el verdadero dharma, o, si se quiere, el único dharma o deber moral, es el de la libertad mediante el ejercicio de la ahimsā, es decir, de la no-violencia y el respeto a la vida. En su biografía, Gandhi nos cuenta cómo los versos del segundo capítulo de la Gìtā le causaron una profunda impresión, sobre todo estos, que muestran la necesidad del desapego:

Cuando se analiza el objeto de los sentidos

se advierte que de ellos brota la atracción;

y de la atracción nace el deseo, que a su vez

inflama la fiera pasión. La pasión alimenta los vicios

y, entonces, la memoria queda traicionada, deja

que se ausenten los propósitos nobles y mina el espíritu ${ }^{14}$.

Pero, además, para Gandhi esa guerra con que se abre el poema hay que interpretarla de manera simbólica. El campo de batalla que se produce en las cercanías de la antigua Delhi es una lucha entre el bien y el mal que tiene lugar en el campo del alma del hombre, que también es otro campo de batalla. Esa interpretación la han puesto de relieve estudiosos de Gandhi, como Cuenca Almenar o el anteriormente citado biógrafo Stanley Wolpert. Dice, a este respecto, Cuenca:

13 Salvador Cuenca Almenar, «Una justificación de la no-violencia a través de un texto bélico: Gandhi lee el Bhagavad Gita», en Eikasia. Revista de Filosofia, núm. 50, julio de 2013, p. 283. Está disponible en Internet en la siguiente dirección: http://revistadefilosofia.com/ numero50.htm

14 Gandhi, Autobiografia, op. cit., p. 66. 
Gandhi subrayaba que el campo de batalla era el cuerpo y el combate se daba entre afectos egotistas, como la cobardía o la acumulación de posesiones y placeres, y los impulsos desinteresados que liberaban de los mismos. Los afectos egotistas se representaban alegóricamente por los personajes comandados por Duryodhana y las tendencias desinteresadas por los aliados de Arjuna. Por ello, Arjuna actúa como un arquetipo de la acción no-violenta que vence a la cobardía de la fuga o de la inacción ${ }^{15}$.

Por su parte a Stanley Wolpert le llama poderosamente la atención la asombrosa imaginación de Gandhi al poner en relación una obra en que se justifica la violencia, la Gĩtā, con el mensaje de Jesús en Sermón de la Montaña, donde insta a poner la otra mejilla a cualquiera que nos hiera. Dice, en este sentido:

Gandhi trató de reinterpretar la más famosa justificación filosófica del asesinato que ofrecía el hinduismo y convertirla en un canto de pasividad cristiana. Al igual que los antiguos lógicos hindúes, procuraba conciliar conceptos opuestos y albergaba la esperanza de que por medio del dulce optimismo de su análisis desarmaría a sus adversarios más acérrimos, ya fueran británicos, musulmanes o hindúes ${ }^{16}$.

Gandhi llegó, por tanto, a Sudáfrica con el bagaje de estas lecturas, pero su interés por conseguir la verdad le obligó a seguir leyendo.

\section{León Tolstoi y su visión de la religión cristiana}

Entre los autores que han influido en el pensamiento de Gandhi se encuentra el conde León Tolstoi. El conocido novelista ruso, una de las cumbres de la

15 Salvador Cuenca Almenar, op. cit., p. 285.

16 Stanley Wolpert, Gandhi, op. cit., p. 49. 
novela realista del siglo XIX, tuvo una fuerte crisis espiritual aproximadamente en la época de finalización de Ana Karenina, novela que empezó a escribir en 1873 y que concluyó en 1877. Visitó en esa época, movido por sus inquietudes, el monasterio de Optina Pustyn y también la Troice Sergieva Lavra para hablar con los monjes y discutir sobre ciertos principios teológicos. Tolstoi estaba convencido de que era necesaria la separación entre la religión y los poderes eclesiásticos. Con la publicación en 1882 de su libro Confesión, al explicar lo que el autor entiende por cristianismo, queda claro su alejamiento de la iglesia ortodoxa. Otro libro, titulado En qué consiste mi fe fue declarado muy perjudicial por la censura eclesiástica, e incluso fue confiscado por la policía. Su visión crítica de la Iglesia y la imposibilidad de publicar esos libros en Rusia no impidió que aparecieran en el extranjero, como así sucedería con la obra en que habría de culminar su interpretación del cristianismo, El reino de Dios está en vosotros ${ }^{17}$.

Paralelamente a esta preocupación por lo religioso, el escritor ruso defendía un tipo de vida en que valoraba más el trabajo manual que el trabajo intelectual. Esto no significa que Tolstoi dejara de escribir, ni mucho menos, ni que dejara de estar preocupado por la literatura y el arte en general -incluso seguiría publicando algunas novelas-, pero lo cierto es que en sus dominios de Jásnaya Polyana él alternaba su oficio de escritor con labores agrícolas como arar los campos, transportar agua, así como cortar y recoger leña. También dejaría de fumar, se haría vegetariano y condenaría la sexualidad, condiciones que, de alguna forma, y salvando todas las distancias, le aproximan a lo que solemos entender como un renunciante y nos recuerdan otras actitudes y decisiones parecidas de Gandhi. Vestido como un campesino, y tras liberar a sus siervos, siempre estuvo preocupado por el pueblo, y ya antes de su crisis religiosa se había interesado por la pedagogía y por escribir obras divulgativas que el pueblo, tras ser alfabetizado, pudiera entenderlas. En aquella Rusia profunda y feudal de los siervos, cuyo estatus se parecía más al esclavismo, terratenientes como Tolstoi trataron de mejorar

\footnotetext{
17 Lev Tolstói, El reino de Dios está en vosotros, Traducción del ruso y prefacio de Joaquín Fernández-Valdés Roig-Gironella, Barcelona, Kairós, 2010. Hasta esta loable iniciativa de la Editorial Kairós, la única traducción que existía en España del libro de Tolstoi data de 1902, que, como señala el traductor Fernández-Valdés «es extremadamente resumida y a todas luces no directa del ruso». Por otra parte, la acentuación en la última sílaba del apellido del escritor -Tolstói- coincide con la pronunciación rusa, y esa es la que figura en la edición de Kairós, así como el nombre propio Lev. Por mi parte, sigo pronunciando y, en consecuencia, escribiendo el apellido del escritor conforme a la acentuación llana que es habitual en castellano, así como León en lo que se refiere al nombre propio.
} 
las condiciones de vida de los campesinos ${ }^{18}$. En este sentido hay que interpretar su obra ¿Necesita el hombre mucha tierra?, una pregunta meramente retórica que apuntaba a la intención que cada vez sentía con más fuerza de desprenderse de sus bienes. Tanto sus ideas religiosas como sociales y altruistas provocaron un conflicto con su esposa y con algunos de sus hijos y un distanciamiento que se acentuaría con el tiempo y que le acompañaría hasta la muerte.

Pero todas esas ideas, y no solo ideas, sino actuaciones, que tanto influirían en Gandhi, ya estaban de alguna forma presentes en la obra más emblemática de Tolstoi, Guerra y paz, concluida en 1869. Dos personajes, de los muchos que aparecen en esta novela, el conde Pierre Bezujov, heredero de grandes posesiones y el príncipe Andrey Bolkonsky, oficial de los ejércitos del zar son, de alguna manera, dos alter ego del escritor, pues reflejan aspectos de su vida y de su pensamiento. Recordemos que Tolstoi, aparte de aristócrata y terrateniente, también fue militar, destinado al Cáucaso, y estuvo en los comienzos de la guerra turcorusa. Pierre y Andrey son amigos, y en un momento determinado, cuando se habla de enfrentarse a los ejércitos franceses, a Pierre no le parece bien guerrear contra "el hombre más importante del mundo», es decir, contra Napoleón, al que admira, con el único pretexto de que Rusia deba ayudar a Austria e Inglaterra. A Andrey le resultan ingenuas las reflexiones de su amigo, y le recrimina con esta afirmación: «si todo el mundo luchase por convicción, no habría guerra, no habría guerra» ${ }^{19}$, lo que significa que, si se pensaran bien las cosas, no habría gente disponible para ir a la guerra. La visión crítica que Tolstoi ofrece sobre la guerra -es decir, esa irracionalidad que lleva a los seres humanos al matadero, sin saber muy bien por qué motivos- está presente en esta y en otras escenas de la novela. A continuación, Pierre le pregunta a Andrey

-Bueno, pero usted ¿por qué va a la guerra?

-¿Por qué voy? Pues no lo sé, Hay que ir. Además, voy...

\footnotetext{
18 «Tolstoi creció en una familia rusa, noble y terrateniente. Sin embargo, renunció a sus privilegios en la Corte y liberó a sus siervos, haciendo de su propiedad de Yásnaia Poliana una escuela para los hijos de los campesinos» (Pere Ortega y Alejandro Pozo, Noviolencia (sic) y transformación social, Barcelona, Icaria, 2005, p. 64).

19 León Tolstoi, Guerra y paz, traducción de Víctor Andresco, Madrid, Alianza, 2008, tomo I, p. 47.
} 
Se interrumpió.

-Voy porque la vida que llevo aquí, esa vida... jno es para mí! ${ }^{20}$

Andrey acaba de responder con una justificación puramente personal sobre los motivos que pueden impulsar a alguien para ir a la guerra. Marcha a la contienda como quien escapa de algo y se aferra a un clavo ardiendo, pues es infeliz en su matrimonio y le asquea la vida mundana y frívola de los salones de San Petersburgo y de Moscú.

Pierre Bezujov es quizá, de los dos personajes, el que más refleja las inquietudes de Tosltoi, su insatisfacción ante la realidad y ante las eternas y terribles preguntas de la existencia: «¿Qué debemos amar? ¿Qué debemos aborrecer? ¿Para qué vivimos? ¿Qué represento yo? ¿Qué es la vida? ¿Qué es la muerte? ¿Cuál es la fuerza que lo rige todo?» ${ }^{21}$ Es decir, Pierre se preocupa por encontrar la verdad, como le ocurre al autor de la novela, el conde Tolstoi, y como le ocurrirá décadas después al joven Gandhi. Si al principio Pierre admira a Napoleón, cuando llega a conocer de cerca la guerra, es decir, sus desastres, ve en Bonaparte una ser dañino, un enemigo público universal al que desea matar.

Esta visión negativa de la guerra y de todas las guerras ya estaba presente en otra novela anterior de Tolstoi, Relatos de Sebastopol, narraciones que reflejan la experiencia directa que el autor ruso, como militar, tuvo en la campańa del Cáucaso.

Pero, además, este personaje de Guerra y paz, Pierre, se preocupa en sus posesiones por mejorar las condiciones de vida de sus campesinos, de liberarlos, de que tengan una vivienda mejor, y de que los hijos de estos campesinos puedan estudiar. Todo ello provoca la indignación de otros aristócratas terratenientes, que ven en esa actitud y en esas medidas una poderosa amenaza para sus intereses y privilegios.

Como vemos, en la vida y en la obra de Tolstoi hay inquietudes y prácticas -la preocupación por los oprimidos, la organización de granjas donde se practica una especie de comunismo, el rechazo de la violencia, la valoración del trabajo

20 Ibid.

21 Ibid., p. 506. 
manual-, que coinciden, precisamente, con algunas que experimentará el joven Gandhi en su búsqueda de la verdad. Esa influencia de Tolstoi en Gandhi vendría de la mano de la lectura del libro del escritor ruso El reino de Dios está en vosotros.

\section{El reino de Dios está en vosotros, de León Tolstoi}

Esta obra fue escrita entre 1890 y 1893 . Fue censurada en Rusia por el poder del Estado y el poder de la Iglesia, por lo que solo pudo difundirse y conocerse clandestinamente. Sin embargo, su impacto fue tan grande que en poco tiempo fue traducida y publicada en el extranjero. Más tarde, la propagación de estas ideas en ese libro y en otros sobre asuntos de religión, además de sus críticas no solo a la Iglesia sino también al Estado, le costaría a su autor ser excomulgado en 1901 por el Santo Sínodo de la iglesia ortodoxa. Este hecho produjo demostraciones públicas de simpatía que las autoridades trataron de silenciar prohibiendo a los periódicos destacarlas.

Una versión inglesa de El reino de Dios... fue la que leyó Gandhi, hacia el año 1896, si aceptamos los datos que uno de sus biógrafos más documentados, Stanley Wolpert, ofrece en su estudio ${ }^{22}$. Gandhi se hallaba en Sudáfrica cuando, en plena búsqueda de la verdad, quedó fascinado por las ideas que contiene el libro de Tolstoi. También por esos años ya había fundado el Natal Indian Congress y se estaba convirtiendo en el líder político de los emigrantes de la India. Téngase en

22 «Ocho ańos antes [de la lectura de Hasta esto último, de John Ruskin, que tuvo lugar en 1904], Gandhi había quedado "abrumado" por El reino de Dios está dentro de ti (sic), al leer la obra por primera vez durante su visita inicial al Transvaal» (Stanley Wolpert, op.cit., p. 96). No hay mucha coincidencia entre los biógrafos de Gandhi sobre la fecha exacta en que este debió leer la obra de Tolstoi. Woodcock dice textualmente: «El primero [de los escritores occidentales que leyó en Sudáfrica] fue Tolstoi, cuyo libro El reino de Dios está dentro de ti leyó en 1893" (George Woodcock, Gandhi, Barcelona, Grijalbo, 1973, pp. 35-36). Cuesta creer que, si el libro del autor ruso fue terminado en 1893, en ese mismo año Gandhi leyera la traducción al inglés. Es mucho más creíble la fecha de 1896 a la que se refiere Wolpert, pues para ese año ya le había dado tiempo al libro, que clandestinamente circulaba por Rusia, para salir al extranjero y ser traducido y publicado en otras lenguas. Por su parte Heimo Rau (op. cit.) no indica datos cronológicos sobre la lectura de este libro por Gandhi. Hay que tener en cuenta que Gandhi, en sus memorias, y en la que se basan sus biógrafos, no suele ofrecer precisión sobre fechas salvo en casos muy señalados. 
cuenta que todas las ideas que existen en este libro y en otras obras occidentales que posteriormente leería el futuro Mahatma, no hacían sino abonar un campo de cultivo que había comenzado a brotar con sus lecturas, durante sus años en Londres, de la Gĩtā y del Sermón de la Montaña.

En su autobiografía, en su segunda parte y, en concreto, en el capítulo XV -titulado «Fermento religioso»- Gandhi nos habla de sus muchas lecturas de libros de religión durante su estancia en Sudáfrica, entre las que no faltaban obras de autores cristianos críticos con el cristianismo dominante. Entre estos libros destaca de forma especial el libro de Tolstoi, por el que Gandhi, en su autobiografía, muestra su admiración con estas palabras:

El reino de Dios está en ti, de Tolstoi, me abrumó, dejándome una impresión imborrable. Ante la independencia de criterio, profunda moralidad y autenticidad de ese libro, los que me había prestado Mr. Coates palidecieron hasta la insignificancia ${ }^{23}$.

El título de la obra de Tolstoi está tomado del Evangelio de San Lucas:

Preguntado [Jesús] por los fariseos acerca de cuándo llegaría el reino de Dios, les respondió y dijo: No viene el reino de Dios ostensiblemente.

23 Gandhi, Autobiografía, op. cit., p. 119. Llamo la atención sobre el hecho de que, en este caso, como en otros que he citado anteriormente, el título en español del libro de Tolstoi figura como El reino de Dios está en ti, es decir, la forma pronominal aparece en singular, «en ti», en vez de «en vosotros». Sin embargo, el original ruso, Tsarstvo Bozhie Vnutri Vas, exige el plural, como bien figura en la excelente traducción de Kairós. Para mí esa tendencia a la segunda persona del singular es una especificación que se considera como más efectiva desde el punto de vista espiritual e íntimo, si se piensa en el destinatario lector tomado individualmente. Por lo que respecta a la referencia que hace de Mr. Coates, este es un joven cuáquero que, en Sudáfrica, le proporcionó a Gandhi libros sobre el cristianismo. Con él y con otros cristianos dirigidos por Mr. Baker se reunía Gandhi de vez en cuando para orar (cf. Autobiografía, pp. 106-107), aunque nunca consiguieron convertirle, pues Gandhi, según nos dice, todavía desconocía mucho de su propia religión hindú. 
Ni podrá decirse: Helo aquí o allí, porque el reino de Dios está dentro de vosotros ${ }^{24}$.

En un principio, y como señala Joaquín Fernández-Valdés ${ }^{25}$, la idea de Tolstoi era escribir un pequeño prólogo al Catecismo de la no resistencia del norteamericano Adin Ballou (1803-1890), abolicionista y partidario de la resistencia cristiana no violenta, es decir, también defensor, como lo serían Tolstoi y Gandhi, de la no resistencia al mal con la violencia. El investigador Mario López Martínez menciona a Ballou y a otros autores norteamericanos partidarios de la no violencia, como William Lloyd Garrison, citado también, con reverencia, por Tolstoi ${ }^{26}$. Así que lo que el autor ruso comenzó a escribir como un texto breve, terminaría convirtiéndose en un libro.

El título del primer capítulo de la obra de Tolstoi es ya muy significativo, pues, por su extensión, es casi un resumen del contenido de ese capítulo y una idea fundamental que contiene el libro. Dice así: «Desde que se fundó el cristianismo solo una minoría de personas ha profesado y profesa la doctrina de la no resistencia al mal con la violencia» ${ }^{27}$. Y en ese capítulo ofrece abundantes datos sobre el Catecismo de Ballou, reproduciendo partes de sus preguntas y respuestas, y entre las que destaca esta máxima atribuida a Cristo: «No resistáis al mal con la violencia» ${ }^{28}$. Tolstoi se lamenta de lo silenciadas que quedaron las ideas de Ballou y la nula resonancia que tuvieron en su época, evidentemente porque a los poderes públicos no les interesaban.

24 San Lucas, 17, 20-21. Cito por Sagrada Biblia, versión directa de las lenguas orientales por Eloíno Nácar Fuster y Alberto Colunga, 36ª ed., Madrid, Biblioteca de Autores Cristianos, 1979.

25 Prefacio a Tolstoi, El reino de Dios..., op. cit., p. 8.

26 «Existe toda una literatura [...] en la que se discute y profundiza sobre las posibilidades, límites y potencialidades de los métodos noviolentos [sic]; algunos de estos autores [norteamericanos] son: William Lloyd Garrison, Adin Ballou y Elihu Burrit. Uno de los rasgos generales en esa literatura fue que la acción y los métodos noviolentos perseguían la persuasión moral o espiritual de los adversarios» (Mario López Martínez, «La noviolencia [sic]: una forma de autogestión de la resistencia civil», estudio recogido en Gene Sharp, The Politics of Nonviolence action, Boston, Porter Sargent, 1973, 3 vols., p. 174, cf. http://www.ugr. es/ - mariol/files/publicaciones/capitulos_de_libro/noviolencia/41.pdf

27 Tolstoi, op. cit., p. 17.

28 Ibid., p. 34. 
En El reino de Dios está en nosotros se pone de manifiesto que la doctrina de Cristo y sus enseñanzas del Sermón de la Montaña no tienen nada que ver con la actuación de los que se llaman cristianos (léase también, Estados cristianos) a lo largo de la Historia, con sus guerras y sus acciones violentas de todo tipo. Como señala Fernández-Valdés:

Tolstói carga contra dos instituciones que, a lo largo de la historia, en su opinión, han perjudicado enormemente a la humanidad y a la comprensión cristiana de la vida, porque se fundamentan en el empleo de la violencia: la Iglesia y el Estado ${ }^{29}$.

Para el autor de Guerra y paz la no resistencia constituye la esencia del cristianismo y sitúa en el siglo IV el momento de la perversión y corrupción de la Iglesia cuando esta se unió al poder del Estado. «Las Iglesias -dice Tolstoi- han sido siempre y no pueden dejar de ser instituciones no solo ajenas a las enseńanzas de Cristo, sino incluso hostiles a ellas» ${ }^{30}$.

En los capítulos siguientes las críticas del escritor ruso hacia esa comprensión errónea del cristianismo se dirigen hacia los creyentes y hacia los hombres de ciencia, y pone de relieve las contradicciones que existen entre lo que se entiende como conciencia cristiana y lo que sucede, se justifica y se lleva a la práctica en la realidad, por ejemplo, en la explotación del hombre por el hombre:

Todos somos hermanos, pero aun así cada mañana un hermano o una hermana me vacía el orinal. Todos somos hermanos, pero por la mañana me es imprescindible un puro, azúcar, un espejo y otros objetos en cuya fabricación mis hermanos y hermanas, iguales a mí, han perdido y pierden la salud; sin embargo, yo sigo utilizando tales objetos ${ }^{31}$.

29 Prefacio a Tolstoi, El reino de Dios..., op. cit., p. 8.

30 Tolstoi, El reino de Dios..., p. 92.

31 Ibid., p. 147. 
Sucede, así, que el mensaje de Cristo ha sido tergiversado y pervertido. Se ha destruido la concepción cristiana de la vida, la original, la que se basa en la verdad y en el amor a los semejantes. Y donde más se manifiesta esta perversión es en la utilización de la violencia y de su máximo exponente, la guerra, es decir, de aquello que practica la violencia estatal y militar. Hombres que se consideran cultos e instruidos - dice Tolstoi- conciben, por inercia y por conveniencia, que dentro del orden social establecido debe existir la guerra, el armamentismo y el servicio militar obligatorio. De esos hombres, es verdad que unos creen que la guerra se puede solucionar con medidas diplomáticas, sin embargo, otros consideran la guerra como algo terrible, pero inevitable, y otros van más allá, pues creen que la guerra es algo benéfico y deseable. Con lo cual, la humanidad, para el escritor ruso, con las guerras retrocede miles de años, y vuelve a situarse en aquel estadio de la evolución en que los primitivos se comportaban de una forma instintiva y brutal. Es como si el desarrollo de la civilización y mensajes como los de los evangelios no hubieran existido. De ahí que en los siguientes capítulos del libro Tolstoi se centre en sus críticas hacia el servicio militar obligatorio y, en general, al Estado, institución que, si bien considera que, si en un tiempo tuvo su razón de ser para agrupar a individuos en comunidades y defenderse de amenazas exteriores, ahora ya no tiene sentido. Vemos aquí cómo resalta la ideología ácrata - un anarquismo cristiano- en la que derivó el escritor. En consonancia con el pensador norteamericano Henri David Thoreau (1817-1862) que tanto influyó en él, Tolstoi predica la desobediencia civil y e invita a ser insumisos ante un Estado que, con sus leyes, nos pide que actuemos de forma contraria a la ley de Dios. El largo título del capítulo X, es en sí, todo un resumen de esta filosofía:

La inutilidad de la violencia estatal como instrumento para suprimir el mal. El avance moral de la humanidad se logra no solo mediante el conocimiento de la Verdad, sino también el surgimiento de una opinión pública ${ }^{32}$.

Las leyes estatales son temporales, cambiantes y arbitrarias, mientras que la ley divina del amor es eterna e inmutable. El autor de Guerra y paz considera

32 Ibid., p. 273. En nota a pie de página, el traductor, Fernández-Valdés, aclara que «En ocasiones Tolstói emplea la expresión "opinión pública" en el sentido de "moral social" o "valores sociales"". 
que todo cristiano debe avanzar hacia la perfección, es decir, hacia la Verdad y hacia el amor, por lo que debe desobedecer, aunque siempre de forma pacífica, aquellas leyes estatales que infringen la ley divina.

En sus extensas "Conclusiones», que llevan el llamativo subtítulo de "Arrepentíos, porque el reino de Dios está cerca, a las puertas», Tolstoi desarrolla su visión crítica sobre la sociedad rusa y sus instituciones: gobernadores, jueces, ejército, policía, sin perder de vista la máxima autoridad, el zar, como responsables de toda una cadena de injusticias que abruman al pueblo, sometiéndolo a humillaciones, torturas, ejecuciones, que el autor ruso califica limpia y llanamente de asesinatos. Toda esa violencia existe bajo la justificación de mantener las leyes y el orden establecidos, unas leyes y un orden y unas sentencias destinadas a sostener los privilegios de las clases dominantes, de los aristócratas y terratenientes ante las justas peticiones de los campesinos. Especial hincapié vuelve a hacer en lo aberrante del servicio militar obligatorio. Incluso él mismo cuenta, con sus excelentes dotes de narrador, haber asistido, por azar, al cumplimiento de ejecuciones, así como al reclutamiento forzoso de pobres campesinos. La idea de Tolstoi es que, desde el último policía y soldado, que es quien tiene que ejecutar órdenes injustas contra el pueblo, es decir, contra sus hermanos, hasta los jueces, gobernadores y el propio zar, tomados individualmente, pueden ser, aparte de cristianos, personas bondadosas que consideran que esas leyes y esas sentencias son necesarias e inamovibles. En definitiva, ese no es, para Tosltoi, el reino de Dios, no es el reino del amor ni de la verdad. Si toda esa cadena que va desde el zar hasta el último soldado o policía fuera consecuente con las enseñanzas de los Evangelios sobre el amor a los semejantes y la no violencia, entonces sí que podría hablarse del reino de Dios. Junto a las citas de San Mateo y de San Lucas, cierra así Tolstoi su libro:

El único sentido de la vida del hombre reside en servir al mundo contribuyendo a que el reino de Dios sea establecido. Y ello se producirá únicamente cuando cada individuo reconozca y profese la Verdad ${ }^{33}$.

33 Ibid., p. 415. 
Por el subtítulo de estas conclusiones - «Arrepentíos, porque el reino de Dios está cerca, está a las puertas»- cabe pensar que ese anarquista cristiano que fue Tolstoi estaba convencido de que la Verdad pronto se terminaría imponiendo en las naciones y que estas acabarían abandonando la injusticia, la violencia y las guerras. Tolstoi murió en 1910, y no pudo ver toda la sarta de guerras, matanzas y genocidios que hacen del siglo XX uno de los períodos más aterradores y vergonzosos de la historia de la Humanidad. Y si echamos una mirada a la actualidad, con sus fanatismos y con la amenaza nuclear, que puede convertir este planeta de la noche a la mañana en una costra sin vida, vemos que el reino de Dios está, todavía, muy lejos de conseguirse.

Pero lo cierto es que el libro de Tolstoi influyó en aquel joven abogado indio que estaba llamado a ser una de las figuras emblemáticas de la resistencia pasiva, de la desobediencia civil, de la no violencia. En su búsqueda personal de la Verdad, de la Verdad con mayúsculas, a Gandhi le impresionó el libro del escritor ruso, con el que tendría una breve, pero intensa, correspondencia epistolar.

\section{La Carta a un hindú, de Tolstoi y la correspondencia epistolar entre el autor ruso y Gandhi}

El indio Tarak Nath Das era enemigo del dominio británico en la India y dirigía una revista titulada The Free Hindustan. Escribió en 1908 una carta a León Tolstoi pidiéndole su opinión sobre las injusticias cometidas por Inglaterra y afirmando que solo con la violencia como método de lucha era posible librarse de esa opresión. Tolstoi le contestó con una larga carta que es conocida como Carta a un hindú. Las ideas expuestas en esta carta están muy en consonancia con las que figuran en su libro El reino de Dios está en vosotros, y vienen a ser como un resumen de toda su doctrina sobre la no violencia y sobre el amor, entendiendo amor como la comunión y la solidaridad que debería existir entre todos los seres humanos. Pero la extensa Carta a un hindú ofrece, además, una novedad, que sin duda debió complacer sobremanera a Tarak N. Das, pues la carta comienza con una cita de los Vedas y cada apartado aparece presidido por citas de Krishna, con lo cual Tolstoi, que había leído a Schopenhauer y sabía de su conocimiento 
de las Upanishads, ponía muy hábilmente en relación sus ideas con los libros sagrados hindúes. Además, Tolstoi recomienda a los indios que no caigan en los mismos errores que los occidentales, es decir, que, en su liberación, no empleen métodos violentos ni practiquen la guerra. Con el tiempo, Tarak evolucionaría ideológicamente y se convertiría en amigo y seguidor de Gandhi.

Gandhi ya había leído, como hemos dicho, El reino de Dios está en vosotros, y fue a raíz de la lectura de Carta a un hindú de Tolstoi cuando comenzó su correspondencia epistolar con el escritor ruso. He seguido la recopilación de las cartas entre Gandhi y Tolstoi que ofrece la investigadora brasileña Belkiss J. Rabello, especialista en Tolstoi ${ }^{34}$. Registra cuatro cartas de Gandhi a Tolstoi y tres de Tolstoi a Gandhi. La primera de Gandhi está fechada el 1 de octubre de 1909 y la última el 15 de agosto de 1910. La primera de Tolstoi es del 7 de octubre de 1909 y la última está escrita el 7 de septiembre de 1910, es decir, justo un mes antes del fallecimiento de Tolstoi, si atendemos al calendario juliano ${ }^{35}$. Es una lástima que esta correspondencia tuviera lugar en la fase final de la vida del escritor ruso, aquejado por problemas de salud, pues todo hace pensar que si la muerte le hubiera venido a buscarle años después esa correspondencia con Gandhi se hubiera enriquecido, si cabe, todavía mucho más. Ambos, Tolstoi y Gandhi, se profesaban una mutua admiración.

En resumen, el contenido de la primera carta de Gandhi es el siguiente: Gandhi le informa a Tolstoi de las penosas condiciones de vida que soportan los «indios británicos» (sic, «British Indian») en el Transvaal, debido a una serie de leyes injustas, y de lo que él y otros amigos están haciendo conforme a la doctrina de la no violencia y de cómo los indios que se oponen a esas leyes injustas tienen que soportar ser encarcelados, incluso sometidos a trabajos forzados. Afirma que actualmente hay más de cien «resistentes pasivos» en el Transvaal. Confía Gandhi que la resistencia pasiva vencerá y le pregunta qué piensa sobre la creación de una posible suscripción sobre el tema de la no violencia. Por último, le dice que ha recibido una copia de su Carta a un hindú y le pide permiso para traducirla y editar 20.000 ejemplares. Discute Gandhi humildemente a propósito de las ideas negativas que Tolstoi vierte en su Carta a un hindú sobre la reencarnación,

34 Cf. Belkiss J. Rabello, "Correspondência entre L. N. Tolstói e M. K. Gandhi», en Cadernos de Literatura em traduçâo, núm. 9, [¿̇2009?] pp. 85-113. El estudio está reproducido en la siguiente dirección de Internet: http://www.revistas.usp.br/clt/article/viewFile/49448/53527 35 En el citado estudio de Rabello, las cartas de Gandhi aparecen en su versión original en inglés y su correspondiente traducción al portugués, y las de Tolstoi en su versión original en ruso y su traducción al portugués. 
porque intenta disuadir al lector sobre esa creencia, preguntándole si verdaderamente ha estudiado esa cuestión, recordándole que para muchos indios de la resistencia pasiva su creencia en la reencarnación fue todo un asidero y una forma de mantenerse firmes.

La respuesta de Tolstoi llega en su carta de 7 de octubre de 1909. Se muestra entusiasmado por haber recibido la carta de Gandhi y comprobar la existencia de esa lucha que mantienen sus colegas y amigos en el Transvaal: esa lucha de «la dulzura contra la brutalidad, de la humildad y del amor contra la arrogancia y la violencia» ${ }^{36}$. Por lo que se refiere a la reencarnación, considera que esa creencia nunca podrá ser tan firme como la fe en la inmortalidad del alma y en la justicia y el amor de Dios. De todas formas, le dice que, si quiere, puede eliminar el término reencarnación en la traducción de su Carta a un hindú.

La siguiente carta de Gandhi, del 11 de noviembre de 1909, está escrita desde Londres (a donde ha viajado para gestionar algunas de las protestas de los indios contra las leyes injustas de Sudáfrica). Le agradece sus comentarios, se preocupa por su estado de salud y le adjunta un ejemplar del libro que un inglés, llamado Doke, ha escrito sobre él (sobre Gandhi), y en donde se refleja esa lucha que los indios, conforme a la resistencia pacífica, mantienen en Sudáfrica. Doke no puede ser otro sino el reverendo Joseph J. Doke, autor de un libro sobre Gandhi titulado An Indian Patriot in South Africa, publicado en Londres en 1909. Gandhi le pide a Tolstoi su opinión sobre esta obra, y, al mismo tiempo, le solicita su influencia para popularizar el movimiento si los hechos del libro de Doke le parecen justificados, pues

[...] De tener éxito, no solo sería un triunfo de la religión, el amor y la verdad sobre la irreligión, el odio y la falsedad, sino que muy probablemente sirviera como ejemplo para los millones de seres que viven en la India o para gentes en otras partes del mundo que pudieran estar oprimidas ${ }^{37}$.

36 Belkiss J. Rabello, op. cit., p. 94. Traduzco del portugués al castellano.

37 Sigo la traducción de esta carta tal, tal y como figura en el apéndice de la edición de Kairós de El reino de Dios está en vosotros, de Tolstoi, op. cit., p. [2]. Se desliza un error en la fecha que aparece al comienzo de la reproducción de esta carta, pues no es la del 10 de noviembre de 1901, sino la del 11 de noviembre de 1909. 
La editora de estas cartas, Belkiss J. Rabello, nos dice en nota a pie de página que «Tolstoi, que estaba enfermo, nunca pudo responder a esta carta de Gandhi fechada el 11 de noviembre de 1909»"38.

La tercera carta de Gandhi está escrita el 4 de abril de 1910, desde Johannesburgo. En ella le comunica a Tolstoi que le envía adjunto un libro que ha escrito y que ha traducido de su versión original en gujarati, un original que, además, ha sido confiscado por el gobierno de la India. Gandhi espera la opinión de Tolstoi sobre lo que contiene el libro y le adjunta también copias de la traducción de Carta a un hindú. Por la contestación siguiente de Tolstoi, sabemos que el libro que le envía es Indian Home Rule.

Esa respuesta del escritor ruso está escrita el 8 de mayo de 1910. Le dice que ha leído el libro y le ofrece este breve, pero significativo comentario:

He leído el libro con enorme interés porque creo que el tema que trata usted en él -la resistencia pasiva- es una cuestión de gran importancia, no solo para la India sino para toda la humanidad ${ }^{39}$.

Se disculpa Tolstoi por no poder extenderse más en la carta, debido a su estado de salud, promete hacerlo cuando mejore, y se despide como «Su amigo y hermano".

La siguiente y última carta de Gandhi a Tolstoi refleja la satisfacción con que ha recibido las palabras del autor ruso. Además, le explica por qué ha decidido llamar al nuevo ashram la "Granja Tolstoi», "como un estímulo para un ulterior esfuerzo para vivir de acuerdo con el ideal que ante el mundo presenta usted $»^{40}$. Termina reconociendo el interés que Tolstoi demuestra hacia la resistencia pasiva que se desarrolla en el Transvaal, y se despide de él como «su humilde siervo».

38 Belkiss J. Rabello, op. cit., p. 96.

39 Tolstoi, El reino de Dios está en vosotros, op. cit., apéndice, p. [6].

40 Como esta carta no aparece en le edición de Kairós, traduzco de la versión que ofrece Rabello, op. cit., p. 104. 
La última carta de Tolstoi está fechada en Kochety y lleva fecha de 7 de septiembre de 1910, es decir, un mes antes de su muerte. Curiosamente, es la más larga de todas las cartas cruzadas entre él y Gandhi, y casi que podemos considerarla como parte muy importante del legado intelectual y espiritual del escritor ruso. Declara haber recibido el periódico Indian Opinion y se alegra porque habla de "quienes renuncian a toda resistencia por la fuerza» ${ }^{41}$. Ahora que se ve cercano a la muerte se afirma en la no violencia, que es «la doctrina de la ley del amor no pervertida por sofismas». Para Tolstoi el amor, la unidad de los seres humanos entre sí, representa «la única ley de la vida», que está presente en todas las filosofías orientales y occidentales, y, en clara alusión al Sermón de la Montańa, recuerda que Cristo lo dijo con total claridad: que el empleo de la fuerza es incompatible con el amor. Ninguna religión ha definido con mayor claridad la ley del amor, y, sin embargo, la civilización cristiana, es decir, las naciones cristianas, han olvidado, en clara contradicción, esa ley del amor, pues han empleado la fuerza en sus variadas manifestaciones, "como gobiernos, tribunales y ejércitos, que se aceptan como necesarios y apreciados». Reconoce que los seres humanos siempre se han dejado llevar por la fuerza como fundamento principal de su ordenamiento social, pero todo eso no tiene nada que ver con el mensaje de Cristo, que se ha olvidado.

A continuación, y muy en consonancia con las ideas expresadas en El reino de Dios..., la Carta a un hindú y otras obras, pasa Tolstoi a expresar propuestas que tienen que ver con su anarquismo de corte cristiano: «...que cese toda aplicación obligatoria de impuestos, así como la abolición de todas las instituciones legales y de la policía y, por encima de todo, de las instituciones militares» ${ }^{42}$.

Se refiere a una escena que contempló meses atrás en una escuela de muchachas de Moscú, en un examen de religión, donde estaban presentes el profesor y también un arzobispo. Se hablaba de los diez mandamientos, y en lo que se refiere al «No matarás» preguntó el arzobispo: «PProhíbe la ley de Dios matar siempre y en todos los casos?», y las muchachas, bien aleccionadas por su profesor, contestaron: «No siempre, pues se permite en casos de guerra y en las ejecuciones». Sin embargo, una de las muchachas contestó muy decidida: «Siempre!», ańadiendo que incluso está prohibido matar en el Antiguo Testamento, «...y

41 Cito por la edición de Kairós, Tolstoi, El reino de Dios..., op. cit., p. [7]. Si no se indica cambio de página, las citas siguientes de esta carta pertenecen a la misma página anteriormente citada.

42 Ibid., p. [9]. 
que Cristo no sólo nos prohibió matar, sino en general causar cualquier daño a nuestro prójimo» ${ }^{43}$. Cuenta Tolstoi, basándose en el testimonio fidedigno de un amigo, que ante esta respuesta el arzobispo prefirió callar «y la victoria fue de la muchacha».

Para resolver los problemas del mundo -dice Tolstoi- no se puede olvidar lo que dijo esa muchacha. Y hace después una referencia a esa labor no violenta que Gandhi y otros están haciendo en el Transvaal, algo muy importante que «el mundo puede ahora compartir, y de la que pueden participar no solo los cristianos, sino todos los pueblos de la Tierra». Afirma que en Rusia hay un movimiento parecido, y cada año aumentan los rechazos a cumplir el servicio militar obligatorio. Para Tolstoi, "tanto unos como otros pueden decir: Dios está con nosotros, y Dios es más poderoso que el ser humano»" He ahí una clara referencia que hace el autor ruso sobre el verdadero reino de Dios. Ya en el colofón de su extensa carta cree el autor de Guerra y paz que esa contradicción que existe entre lo que preconiza el cristianismo y esa preparación de ejércitos para ocasionar carnicerías «se revelará a la luz del día en su total desnudez», lo que sin duda amenaza tanto al cristianismo, tal y como se practica, como a los Estados, es decir, amenaza tanto a "sus británicos como nuestros rusos [...] [pues] los gobiernos saben de dónde procede la mayor de sus amenazas y permanecen en guardia y ojo avizor, no solo para preservar sus intereses, sino también para proteger su propia existencia».

\section{Una referencia a John Ruskin y la creación del primer ashram}

Aunque nos obligue a volver unos ańos atrás, quiero destacar el hecho de que en la formación ideológica del futuro Mahatma ocupa un lugar especial la lectura de la obra de John Ruskin Unto this last (Hasta este último), locución que aparece en la versión de la Biblia de King James, de la Iglesia de Inglaterra y de principios

43 Ibid., p. [10].

44 Ibid., p. [11]. 
del siglo XVII. Está en el Evangelio de San Mateo, extraída de la parábola de los obreros enviados a la viña ${ }^{45}$.

El libro se lo regaló Henry Polak en octubre de 1904 en la estación de Johannesburgo, cuando Gandhi se disponía a tomar un tren con destino a Durban. Polak recomendó a Gandhi que lo leyera, como así hizo. Gandhi declara en su autobiografía que leyó el libro de un tirón esa noche y que decidió cambiar su vida de acuerdo con los ideales del libro ${ }^{46}$. Ruskin estaba preocupado por la reforma social, rechazaba la degradación de las ciudades industriales y valoraba el trabajo rural y manual, muy importante para la creatividad del ser humano. Así, para Gandhi, y tal y como lo expresa en su autobiografía, los principios que extrae de la lectura de Ruskin son los siguientes:

1. Que el dios individual está implícito en el dios de todos. 2. Que el trabajo del abogado tiene tanto valor que el del barbero, en el sentido de que todos tienen derecho a ganarse la vida con su trabajo. 3. Que una vida de trabajo, por ejemplo, la vida del labrador o del obrero, es la vida que merece vivirse ${ }^{47}$.

Como señala George Woodcock, «solo la primera de estas ideas está explícita en Unto this last. Las otras dos se hallan, como mucho, implícitas» ${ }^{48}$. Este autor pone de relieve que Gandhi ya estaba preparado antes de leer la obra de Ruskin, pues: «... había llegado a comprender que la vida de un abogado acomodado, la

45 Si seguimos la Sagrada Biblia Católica, más arriba citada, la historia es como sigue. El amo, a lo largo del día y en distintas horas, va enviando a trabajar a su viña a obreros que encuentra en la plaza. Después, a la hora de pagar, da el denario convenido lo mismo al que estuvo trabajando todo el día que al último que contrató y solo trabajó una hora. Cuando uno que trabajó todo el día protesta por cobrar lo mismo, el amo le responde: «Amigo, no te hago agravio; ¿no has convenido conmigo en un denario? Toma lo tuyo y vete, Yo quiero dar a este postrero lo mismo que a ti: ¿No puedo hacer lo que quiero de mis bienes? ¿O has de ver con mal ojo que yo sea bueno? Asi, los postreros serán los primeros, y los primeros postreros. Porque son muchos los llamados y pocos los escogidos» (San Mateo, 20, 13-16). He subrayado las frases que considero relevantes en cuanto a la explicación del título de la obra de Ruskin.

46 Cf. Gandhi, Autobiografía, op. cit., p. 239.

47 Ibid.

48 Woodcock, Gandhi, op. cit., p. 38. 
suya de 1904, por ejemplo, resultaba incompatible con su vocación de revolucionario no-violento» ${ }^{49}$.

Así, motivado por estas ideas, el joven abogado quiso poner en práctica los ideales de Ruskin, por lo que compró en 1904 en Sudáfrica una granja de cuarenta hectáreas a la que puso el nombre de «Phoenix». Esa fue la primera de sus ashrams o comunas rurales:

El plan era [...] una extensión de terreno lo bastante grande y alejada del ajetreo de la ciudad [...] cada uno de los trabajadores podía tener su parcela [...] [con] condiciones saludables sin gastos onerosos [...] los trabajadores podían llevar una [...] vida más natural, y las ideas de Ruskin y Tolstoi se combinarían con rigurosos principios comerciales ${ }^{50}$.

Como apunté más arriba, Gandhi ya había leído la obra de Tolstoi El reino de Dios está en vosotros, ocho años antes. No es extraño que otro de esos ashram lo bautizara como la "Granja Tolstoi». La figura del escritor ruso vestido y trabajando como un campesino y sus ideales sobre las reformas que necesitaba el campesinado de su país coinciden en muy buena medida con las de Ruskin.

\section{La Satyāgraha}

La Satyāgraha ${ }^{51}$ supone, para Gandhi, la culminación de todo un proceso intelectual, espiritual y vital muy enriquecedor en el que están presentes las lecturas de la Gìtā, del Nuevo Testamento y de los autores antes citados, autores entre los que destaca, como hemos visto, de forma muy especial, León Tolstoi. Recordemos que esa búsqueda de la Verdad está presente de forma muy clara en el subtítulo de la autobiografía gandhiana: Historia de mis experimentos con la verdad.

\footnotetext{
49 Ibid.

50 «Ourselves», en Indian Opinión, 24 de diciembre de 1904.

51 Prefiero el uso femenino de esta palabra, más extendido así en castellano. No obstante, respeto el masculino en las citas de aquellos textos que emplean este género.
} 
Todo ese río enriquecedor que fluye en el pensamiento de Gandhi se manifestará durante su etapa en Sudáfrica en sus actuaciones para defender los derechos de los indios. Un hito especial en ese activismo fue la creación del periódico Indian Opinion, que vio la luz en 1904, y en donde verterá su pensamiento, que irá conformando lo que entendemos por satyāgraha:

Semana tras semana entregaba mi alma a esas columnas, y divulgaba los principios y prácticas del satyagraha tal y como yo los entendía. Durante diez años, es decir, hasta 1914, exceptuando mis intervalos de mi obligado descanso en la cárcel, difícilmente aparecería una sola vez el Indian Opinión sin un artículo mío ${ }^{52}$.

En la lucha por los derechos legítimos de los oprimidos, a Gandhi, según su autobiografía, no le satisfacía plenamente la expresión «resistencia pasiva», término del inglés usado también en gujarati para referirse a la satyāgraha. Dice Gandhi lo siguiente:

Cuando en una conversación con europeos comprendí que el término «resistencia pasiva» estaba demasiado simplemente construido, que se le suponía un arma para débiles, que podía ser definido como un odio, y que finalmente podía manifestarse por la violencia, tuve que negar todas estas caracterizaciones y explicar la verdadera naturaleza del movimiento indo (sic). Resultó claro que una nueva palabra debía ser acuñada por los indos para designar su lucha ${ }^{53}$.

Nos cuenta Gandhi que, para encontrar un nuevo término, creó un concurso ofreciendo un premio al lector que presentara la mejor sugerencia. Maganlal Gandhi, nieto de un tío de Gandhi y seguidor de este, fue quien creó la palabra Sadagraha, de sat 'verdad', y agraha, 'firmeza', pero para una mayor claridad fue Mohandas quien lo cambió por satyāgraha, 'insistencia o persistencia en la verdad', que es como se conoce para designar la lucha de la resistencia no violenta. Sin embargo, como hemos podido apreciar anteriormente, el término supone también toda una filosofía y concepción de la vida, en donde son fundamentales la búsqueda de la verdad en todos los órdenes y en la práctica de la ahimssā,

52 Gandhi, Autobiografia, op. cit., p. 230.

53 Ibid., p. 253. 
término del sánscrito que hace referencia a la no violencia y el respeto a la vida -lo contrario de la himssā-. A esa conclusión llega tras sus lecturas de la Gìtā, del Nuevo Testamento, y de autores como Tolstoi. Muchos ańos después, en enero de 1946, dos años antes de su muerte, Gandhi dijo ante un grupo de profesores y estudiantes de Madrás que la verdad y la no violencia eran mucho más potentes que la bomba atómica ${ }^{54}$.

El profesor Ganguly destaca en un interesante ensayo la originalidad de Gandhi al haber sabido combinar un método colectivo -la no violencia- "con el poder transformador individual mediante el seguimiento de lo que él llamó la búsqueda de la verdad o el satyāgraha» ${ }^{55}$.

Gandhi protagonizó a lo largo de su vida, como le ocurrió a Tolstoi, una incansable búsqueda de la verdad. Eso le llevaba a experimentar en todos los órdenes: desde la alimentación vegetariana y el alejamiento del deseo sexual (actitud esta última que pueden parecer extravagante, sobre todo a ojos de los occidentales), hasta la ética profesional de un abogado, pasando por el llamamiento a la unidad y al amor entre hindúes y musulmanes y otros grupos religiosos, así como por la vida en comunidad sin distinción de religión y castas en los ashram que fundó y dirigió. Esa búsqueda de la verdad coincidía con la necesidad de encontrar el verdadero reino de Dios en este mundo, por referirnos al título de la obra de Tolstoi aquí estudiada. Por eso, debe quedar bien claro que Gandhi no solo pretendió la independencia de la India. El swaraj (de swa- 'mío' y raj 'la regla') fue un término muy utilizado después de la Primera Guerra Mundial por los liberales británicos y por los moderados indios pensando en el autogobierno, pero de hecho se hablaba más de estatuto de dominio que de independencia total o autogobierno. La mente de Gandhi iba más lejos. Para él suponía la independencia total del yugo inglés, pero, además, como diría una década después cuando ya se encontraba en la India:

Creo en la no violencia pura [...] Creo que la unidad entre hindúes, musulmanes, sijs, parsis, judíos, cristianos y otros es esencial para alcanzar el Swaraj. Creo que la supresión de la intocabilidad es igualmente esencial ${ }^{56}$.

54 Cf. Stanley Wolpert, Gandhi, op. cit., p. 320.

55 Shyama Prasad Ganguly, "Gandhi y su relevancia», en Papeles de la India, Consejo Indio de Relaciones Culturales, Nueva Delhi, vol. 34, núm. 1, 2005, p. 155.

56 «My Limitations», Young India, 12 de septiembre de 1929. Citado por Stanley Wolpert, op. cit., p. 211. 
Aunque fomentó el nacionalismo su mirada estaba puesta más allá: en una fraternidad universal. En ocasiones, cuando tras un llamamiento suyo a la desobediencia civil se producían masacres, él mismo reconocía que la India no estaba aun suficientemente preparada. La búsqueda de la verdad trascendía para él lo meramente político y se convertía en toda una serie de principios filosóficos y religiosos, pero no solo principios teóricos, sino también prácticas consecuentes. Decía que los indios debían cambiar en muchas cosas, y que no bastaba solo con liberarse del dominio británico. Clamó constantemente contra la existencia de la intocabilidad, que consideraba como algo abominable en el hinduismo, y se preocupó por la situación de la mujer y por eliminar los matrimonios entre niños. Pretendía que el político debía actuar con ética, de ahí ese interés por lo religioso. Al empezar a tratar a los políticos indios, ya en el Congreso de Calcuta de diciembre de 1901, se desilusionó, al conocer de cerca «sus mezquinos prejuicios y vanidades» ${ }^{57}$. Como señala uno de sus mejores biógrafos:

Una de las razones de su desilusión con el Congreso de Calcuta había sido ver que la segregación de castas y el prejuicio más cruel del hinduismo contra los «intocables» emponzoñaban lo que debería haber sido la institución más noble de la nación ${ }^{58}$.

Hombres como Tolstoi y Gandhi muestran al género humano que es posible otro mundo, bien distinto del que nos rodea, donde cada día nos sobresaltan y horrorizan las noticias de la discriminación, del odio, del fanatismo y de la guerra. Tolstoi y Gandhi no solo representaron la utopía, sino también la acción, y buscaron ser consecuentes con sus ideas religiosas, éticas y políticas. Sin hombres como ellos, eso que llamamos civilización no sería posible. Como señala Ramin Jahanbegloo en su ensayo La hora de Gandhi:

Gandhi estableció un diálogo mutuo entre lo ético y lo político [...] [pues] estaba convencido de que el proceso de fomentar la libertad individual y la armonía social solo era posible a través de la espiritualización de la política y de la reintegración de esta dentro de la ética ${ }^{59}$.

\footnotetext{
57 Wolpert, op. cit., p. 84.

58 Ibid.

59 Ramin Jahanbegloo, La hora de Gandhi, Barcelona, Galaxia Gutenberg, con prólogo del Dalai Lama y traducción de Ana Cadarso, 2012, p. 26 y pp. 28-29.
} 
La universalidad de Gandhi se manifiesta en la atracción que su figura sigue ejerciendo no solo en su país, sino en el resto del mundo. Judith Brown, en su estudio sobre el Mahatma, lo afirma con palabras parecidas, que hago mías como colofón de este trabajo:

[...] fue un hombre de visión y de acción, que se hizo muchas de las preguntas más profundas a que se enfrenta el género humano en su lucha por vivir en comunidad. [...] Como hombre de su tiempo [...] se convirtió en un hombre para todas las épocas y lugares ${ }^{60}$.

\section{Conclusiones}

1. La estancia de Mohandas Karamchand Gandhi en Londres y sus años transcurridos en Sudáfrica, y ante las injusticias que, como el resto de los indios, padeció en este país, le llevaron a todo un proceso intelectual y espiritual que culminaría con lo que él definió como la satyāgraha o 'insistencia o persistencia en la verdad'.

2. En su práctica de la satyāgraha, y con una actitud sincretista, Gandhi materializó los principios teóricos de la no violencia (la ahimsā) que se expusieron en las Upanishads hinduistas, en la Gītāa, así como la no violencia predicada por Cristo en el Sermón de la Montańa.

3. Aspecto fundamental de este estudio es el análisis de la gran influencia que tuvieron en Gandhi las ideas de León Tolstoi expresadas en el libro El reino de Dios está en vosotros, donde el autor ruso predica la abolición de la guerra y de los ejércitos, y propone la no violencia como la forma más pura de materializar el mensaje evangélico y conseguir el verdadero reino de Dios en este mundo. Recogió Tolstoi, además, las ideas de John Ruskin en Unto This Last y las de

60 Judith M. Brown, Gandhi: Prisoner of Hope, New Haven: Yale University Press, 1989, p. 394. Cito por la versión de Jahanbegloo, op. cit., pp. 26-27. 
Henry David Thoreau en Desobediencia civil, autores que también influyeron en Gandhi, así como otros pensadores contemporáneos que precedieron a los citados. Tolstoi y Gandhi se profesaron mutua admiración y mantuvieron una breve pero intensa correspondencia epistolar, en la que se desarrollan estas ideas y se menciona su influencia en la resistencia pasiva de los indios en Sudáfrica.

4. La vida de Gandhi es una continua búsqueda de la verdad, que no solamente tiene que ver con los derechos de los indios en Sudáfrica y con la independencia de la India, sino con otros aspectos de las ideas, prácticas y comportamiento del ser humano y especialmente entre los indios, como la importancia del vegetarianismo, la necesidad de la abstinencia sexual, la igualdad social sea cual sea la profesión ejercida, el respeto a las otras religiones, la superación de la discriminación entre las castas, la abolición de la intocabilidad, la importancia del trabajo manual y de las labores agrícolas y la creación de ashrams o granjas colectivas como lugar idóneo para desarrollar la satyāgraha. En la creación de los ashrams fue notable la influencia de Tolstoi.

5. En consonancia con lo expuesto anteriormente, Gandhi trascendió con su satyāgraha lo puramente político, y aunque estuvo siempre relacionado con la política y defendió el nacionalismo, fue crítico con ciertos aspectos de la realidad de los indios y propugnó una fraternidad universal.

\section{Bibliografía}

Brown, Judith M. (1989). Gandhi: Prisoner of Hope. New Haven: Yale University Press.

Cuenca Almenar, Salvador (2013). «Una justificación de la no-violencia a través de un texto bélico: Gandhi lee el Bhagavad Gita». Eikasia. Revista de Filosofia, núm. 50, pp. 279-287.

Díez, Fernando (2005). El legado de la India. Madrid: Mandala.

GANDHI (2016). Autobiografia. Historia de mis experiencias con la verdad. Madrid, Gaia.

Ganguly, Shyama Prasad (2005). «Gandhi y su relevancia». Papeles de la India, Consejo Indio de Relaciones Culturales, Nueva Delhi, vol. 34, núm. 1, 2005. 
HeIMO, RAU (1987). Gandhi. Barcelona: Salvat.

Jahanbegloo, Ramin (2012). La hora de Gandhi. Prólogo del Dalai Lama y traducción de Ana Cadarso. Barcelona: Galaxia Gutenberg.

Ortega, Pere y Pozo, Alejandro (2005). Noviolencia y transformación social. Barcelona: Icaria.

PÁniker, Agustín (2014). La sociedad de castas. Religión y politica en la India. Barcelona: Kairós.

Rabello, Belkiss J. [¿2009?]. «Correspondência entre L. N. Tolstói e M. K. Gandhi», en Cadernos de Literatura em tradução, núm. 9, [¿2009?], pp. 85-113. El estudio está reproducido en la siguiente dirección de Internet: http://www.revistas.usp. $\mathrm{br} / \mathrm{clt} /$ article/viewFile/49448/53527

Sharp, Gene (1973). The Politics of Nonviolence action. Boston: Porter Sargent.

Tolstói, Lev (2010). El reino de Dios está en vosotros. Traducción y prefacio de Joaquín Fernández-Valdés Roig-Gironella. Barcelona: Kairós.

Tolstol, León (2008). Guerra y paz. Traducción de Víctor Andresco. Madrid: Alianza.

El pensamiento de Gandhi. Antología (2013). Selección e introducción de David Williams. Barcelona: Olañeta.

Wolpert, StAnley (2003). Gandhi [título original, Gandhis Passion]. Barcelona: Folio. WoOdCock, GeOrge (1973), Gandhi. Barcelona: Grijalbo.

Enviado: 28/12/2017

Aceptado: 4/08/2018

Este trabajo se encuentra bajo una licencia de Creative Commons Reconocimiento-

NoComercial-SinObraDerivada 4.0 